\title{
Performance evaluation of cross-flow turbine for low head application
}

\author{
Bryan Ho-Yan ${ }^{1}$, W. David Lubitz ${ }^{1, *}$ \\ ${ }^{1}$ School of Engineering, University of Guelph, Guelph, Ontario, Canada. N1G 2W1 \\ * Corresponding author. Tel: +1-519-824-4120 ext. 54387, Fax: +1-519-836-0227, E-mail: \\ wlubitz@uoguelph.ca
}

\begin{abstract}
Pico hydro generators are a promising means of providing cost-effective electricity to locations with limited or no availability of grid-supplied electricity. The Firefly design has been employed throughout rural areas of Cameroon and used as a light battery charger. It is hoped to extend the turbine capacity to provide steady baseload output between 100-500 W operating at low head sites (2-10 m). Suitability of the Firefly under these conditions is currently unknown, and the turbine has not been evaluated under conditions of very low head. The study objective was to characterize the performance through laboratory testing under conditions of low head and variable flow rate, in order to determine if the Firefly turbine meets the requirements of users in Cameroon. At this time, construction has been completed of the Firefly turbine and testing apparatus. The testing process and initial Firefly performance results, as well as lessons learned to date, are the focus of this paper. This is the first phase of a larger project seeking to design an optimized pico hydro turbine that balances performance, reliability and ease of manufacture and installation. The Firefly results will be used as a baseline in comparisons to new turbine designs.
\end{abstract}

Keywords: Pico hydro, Cross-flow turbine, Low head, Remote power generation, Firefly.

\section{Introduction}

Rural electrification enhances welfare through increased productivity, health, media access, and education. Studies by the Independent Evaluation Group of the World Bank (2008) have demonstrated this empirically and have also found that the benefits from rural electrification outweigh the cost of investment.

\subsection{Introduction}

Pico hydro systems harness the energy in flowing water at capacities smaller than $5 \mathrm{~kW}$. They are recognized as a viable option to electrify remote areas with regard to economical, environmental, and social perspectives. Pico hydro yields one of the lowest generating costs amongst off-grid energy options (Williams \& Simpson, 2009). Unlike large scale hydropower, there is low environmental impact with pico hydro systems, mainly due to the exclusion of large water containment. Associated large civil works and the displacement of habitats are not required for the commissioning of pico hydro systems. In addition, negative impacts of large reservoirs such as siltation, increased mercury levels, and off-gassing of green house gases from submerged decomposing organic material are avoided (Gunkel, 2009).

\subsection{GREEN STEP e.V in Cameroon}

GREEN STEP e.V. (http://www.green-step.org) is a non governmental organization originating from Germany with the objective to improve rural livelihoods through providing training and co-financing of renewable energy projects, building environmental awareness through education, and sustainable agriculture extension. In 2007, the organization connected with the M'muock village situated in south western Cameroon. The majority of the 70,000 residents of M'muock to do have access to grid-supplied electricity. 
Pico hydro technology has been one of the main focuses and to date, 40 craftsmen have been trained and nearly 10 turbines successfully built. However, after a year in use, only 2 turbines remained in operation at a limited capacity. Observations (Hertlein, 2010) made from these implemented systems include:

- Concerns regarding ownership have arisen, especially in situations where multiple stakeholders (ie. community or multiple household ownership) are involved. The need for smaller systems targeted towards single dwellings has been identified as lines of responsibility are defined more clearly and free-rider issues are mitigated.

- Improvements are needed to reduce the complexity of the design and also increase robustness. End-users may not be made aware of the importance of maintenance; in addition, distances to workshops are far.

- The current systems employ expensive car alternators, car batteries and inverters. These components are also prone to failures, with the wearing down of alternator brushes being the main concern.

- $\quad$ The willingness-to-pay for a pico hydro system is estimated to be $€ 150$.

- Training is required for local construction of pico hydro systems.

Based on the above lessons-learned, the overall project objective is to design a robust and reliable pico hydro system that is affordable at the household level, suitable for household electricity demand, uses locally sourced materials, and can be manufactured locally at a small industrial scale. The operational range is to be $2 \mathrm{~m}$ to $10 \mathrm{~m}$ head, with flow rates of $5 \mathrm{~L} / \mathrm{s}$ to $100 \mathrm{~L} / \mathrm{s}$, and electrical output in the range of $100 \mathrm{~W}$ to $500 \mathrm{~W}$. The initial phase of the project is to characterize the performance of the existing systems at 2-10 m head and variable flow rates, in order to determine the degree to which the current Firefly turbine meets the targets that are required by users in Cameroon, and provide a baseline for comparisons to future designs.

\subsection{Purpose}

The purpose of this report is to present the low-head and variable-flow-rate laboratory test rig implemented at the University of Guelph (Canada) that is used for testing a pico hydro system built to the same specifications as those used in Cameroon. Results from the tests are tabulated. In addition, lessons learned from the Firefly construction process, and recommendations for improving the testing process are identified.

\section{Methodology}

The existing pico hydro systems employed by GREEN STEP e.V. in the field are known as the "Firefly" design. A Firefly unit was constructed in Guelph (Canada) for laboratory testing, according to the instructions of Portegijs (2003). Laboratory testing was conducted on a rig with the ability to vary flow rates and heads within the low head range. Focus was placed on the low head range as the Firefly documentation did not provide performance for heads below 3 m (Portegijs, 2003).

\subsection{Firefly}

The Firefly was designed by Jan Portegis for use in rural Philippines. It consists of a crossflow turbine attached to a car alternator, and was intended strictly for battery charging. 
The turbine has 27 blades supported by circular side plates with a $75 \mathrm{~mm}$ diameter and turbine height of $55 \mathrm{~mm}$ (Fig. 1). A $51 \mathrm{~mm}$ wide nozzle guides the flow to the turbine. The range of operating head is $3 \mathrm{~m}$ to $7 \mathrm{~m}$, and $8 \mathrm{~m}$ to $25 \mathrm{~m}$ with governed flow (Portegijs, 2003).

In the original Firefly design, the field current of the alternator is controlled by 4 incandecsent light bulbs ( $3 \times 20 \mathrm{~W}$ and $1 \times 10 \mathrm{~W}$ ) and switches connected in parallel. Six different resistance values are possible, which allows for optimization of the field current (Portegijs, 2003).

Fig. 1. Runner assembly.

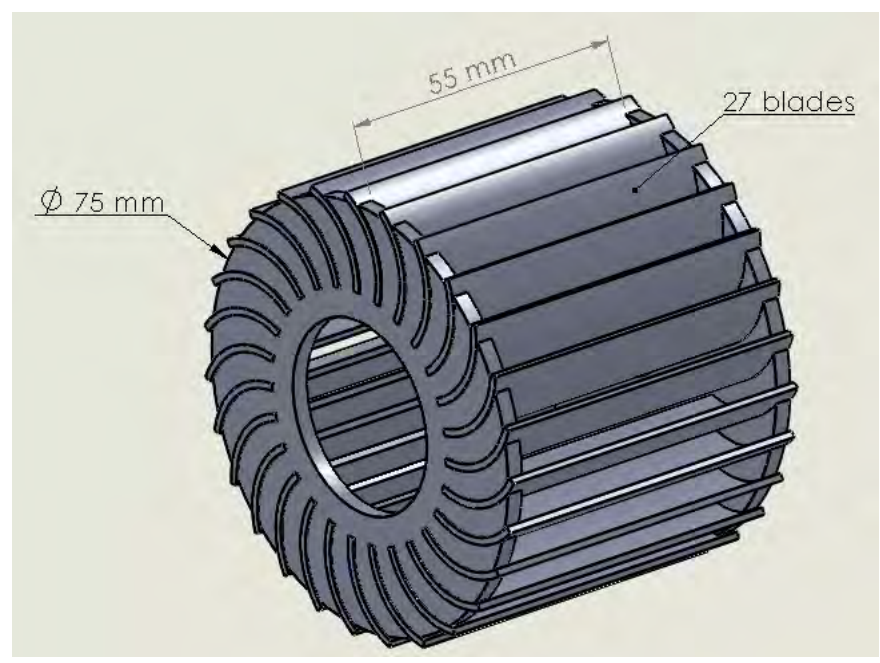

\subsection{Firefly construction}

Construction of the Firefly for testing in Guelph generally followed the design manual (Portegijs, 2003). The cross-flow sidewalls were laser cut rather than hand cut. The blades were manually sheared and formed as per instructions. The turbine assembly was welded instead of soldered, as detailed in the design manual, however this is in agreement with practices used for the Cameroonian units. The nozzle and frame were also fabricated as per instructions. The casing was excluded as the test unit would not be exposed to a harsh field environment. A Valeo model AB180128 automobile alternator was used. All construction (except for laser cutting) took place within the engineering machine shop facilities at the University of Guelph.

Considerable lessons were learned from the build process. Significant skill on the part of the fabricator is required to build these units. Difficulty would be further accentuated by limited resources. The use of jigs, especially for blade cutting and bending, could improve consistency from blade to blade and simplify the turbine assembly: additional practical advice on fabrication would be a useful addition to an updated construction manual. The turbine sidewall fabrication involves cutting multiple curved slots for the attachment and soldering/welding of the curved blades. Consistently cutting the curved slots in the side walls is extremely difficult for unskilled workers (such as university students), which lead us to laser cut these components. It should be noted that skilled workers with metal working experience using appropriate jigs could mitigate much of this concern.

Variability between individual Firefly is also introduced if different models of alternators are used. For example, the joining of the turbine to the alternator shaft differs slightly between the Guelph unit and the instruction manual, owing to a different configuration of the alternator 
shafts. This need to adapt to different alternator models affects the standardization of the build process, complicating construction by forcing builders to veer away from the design manual.

\subsection{Test Apparatus}

The Guelph laboratory test apparatus (shown in Fig. 2) consists of an $1135 \mathrm{~L}(0.9 \mathrm{~m} \mathrm{x} 1.9 \mathrm{~m}$ plan, $0.6 \mathrm{~m}$ height) reservoir elevated on a $3.3 \mathrm{~m}$ high platform. A $10 \mathrm{~cm}$ (4 in) diameter ABS plastic penstock connects the drainage hole at the base of the reservoir to the Firefly. The total length of the penstock pipe from the reservoir to the Firefly is approximately $4 \mathrm{~m}$. The Firefly is located above a receiving reservoir. An electric pump is used to return water to the supply reservoir between tests. With the Firefly in place, the system has a nominal head of 3 $\mathrm{m}$, however, the head can be varied by changing the height of the Firefly while adjusting the length of the penstock.

The Firefly's alternator field circuit was connected to a high capacity $12 \mathrm{~V}$ deep discharge lead acid battery. A resistor was included in the circuit. Changing the resistance of this resistor allowed the field strength to be varied. The power output of the alternator was directly connected to a $2.0 \mathrm{ohm}$ dynamic braking resistor with a $2 \mathrm{~kW}$ capacity.

A Medusa Scientific PowerPro power meter capable of measuring voltage, current and power was connected to the alternator. The PowerPro was connected to a desktop PC, which recorded data at a rate of $4 \mathrm{~Hz}$.

Flow rate is controlled by throttling a needle valve installed at the penstock inlet at the base of the reservoir. Instantaneous reservoir level, and by extension, flow rate out of the reservoir, is measured using a float connected to an ultra-low friction potentiometer (adapted from an anemometer) by a swing arm. The potentiometer is connected to the PowerPro via a voltage divider circuit, so that head and flow rate are recorded simultaneously with voltage, current and power. Before testing, the output of the float sensor is calibrated and a transfer function is derived that outputs reservoir level as a function of the recorded signal.

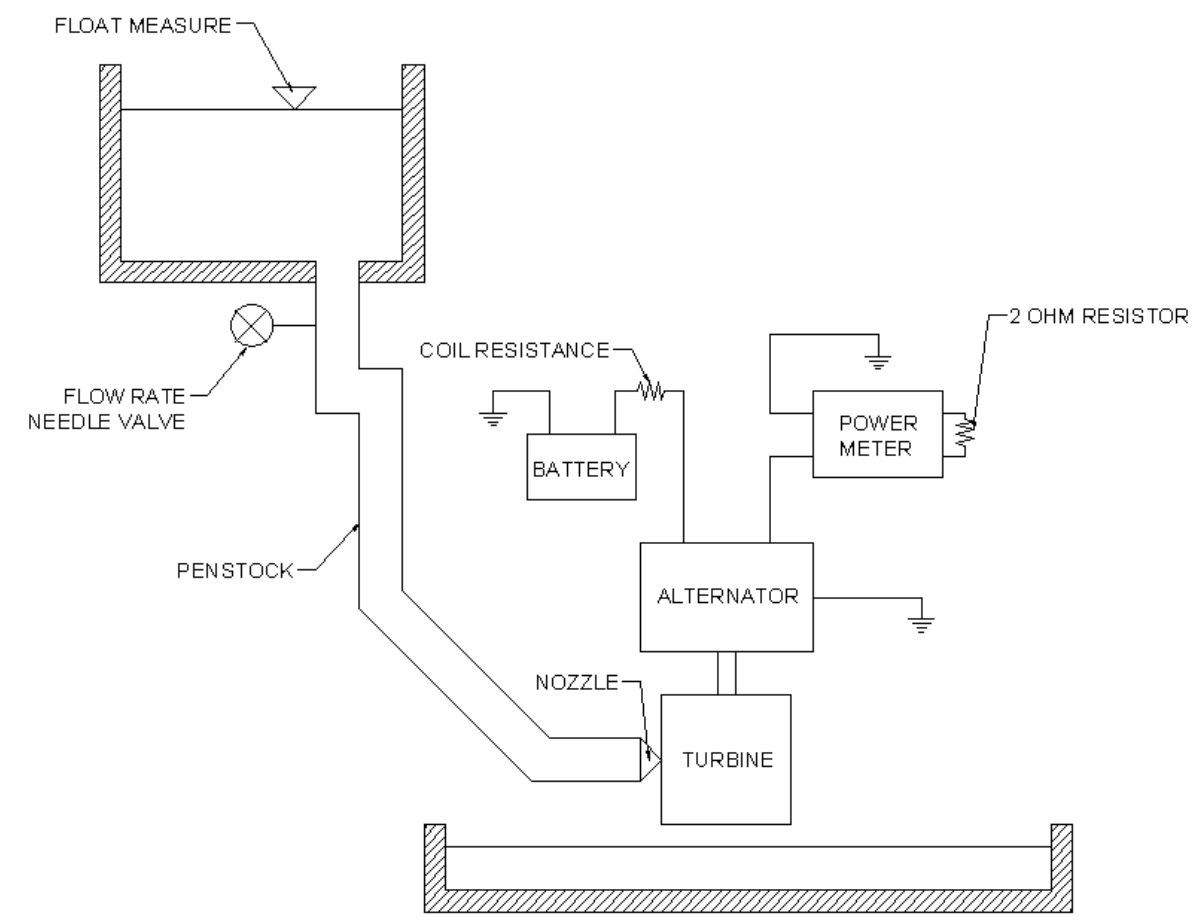

Fig. 2. Layout of test apparatus. 


\subsection{Test Method}

Tests were conducted with flow rates ranging from 5.52 to $5.81 \mathrm{~L} / \mathrm{s}$ and average heads of 3.4 $\mathrm{m}$. The field circuit resistance was varied to determine the optimum resistance to include in the field coil circuit. Resistances used were $0,5,10,20$, and $47 \mathrm{ohm}$.

\section{Results}

The results of the tests are tabulated below in Table 1. Power output from the Firefly under a generally consistent flow rate and head is reported, with varying field resistance.

Table 1. Experimental results

\begin{tabular}{ccccc}
\hline $\begin{array}{c}\text { Coil Resistance } \\
{[\mathrm{ohm}]}\end{array}$ & $\begin{array}{c}\text { Flow Rate } \\
{[\mathrm{L} / \mathrm{s}]}\end{array}$ & $\begin{array}{c}\text { Average Head } \\
{[\mathrm{m}]}\end{array}$ & $\begin{array}{c}\text { Average Power Output } \\
{[\mathrm{W}]}\end{array}$ & Efficiency \\
\hline 0 & 5.61 & 3.40 & 9.39 & $4.8 \%$ \\
5 & 5.81 & 3.39 & 12.15 & $5.9 \%$ \\
10 & 5.52 & 3.39 & 11.60 & $6.0 \%$ \\
20 & 5.73 & 3.39 & 10.70 & $5.3 \%$ \\
47 & 5.58 & 3.39 & 10.14 & $5.2 \%$ \\
\hline
\end{tabular}

Based on the test results, a 5 ohm to $10 \mathrm{ohm}$ field circuit resistance was observed to be the optimal resistance, resulting in a higher average power output than was achieved with higher or lower resistances in the field circuit. The field current control recommended in the design manual is calculated to range from $2.1 \mathrm{ohm}$ to $14.4 \mathrm{ohm}$, which is consistent is consistent with these test results.

Over the entire range of resistances, power output and efficiencies were lower than the predictions of Portegijs (2003). Portegijs predicted but could not test that the Firefly would produce $46 \mathrm{~W}$ at $3 \mathrm{~m}$ head and $5.3 \mathrm{~L} / \mathrm{s}$. It should be noted that a typical alternator would be below its normal operating range, and likely to underproduce the predicted value. Portegijs identified this as a concern, and suggested that his calculated values would be high because of this, for the combination of head and flow rates tested here. This is believed to be one reason for the lower than expected performance during testing.

\section{Discussion}

Given the lower than expected power outputs and efficiency, it is believed that the test Firefly requires modifications to enhance the test results. Construction of the Guelph Firefly must be revisited: it appears that the gap between the nozzle and turbine is higher than other examples of the Firefly. Inspection of the unit after testing showed that realignment is needed of the nozzle with respect to the cross-flow turbine, and that a small amount of nozzle movement was possible. This is considered to be the root of the matter. This demonstrates the criticality of construction training and the need for simplistic designs.

The test results also confirm that at the combinations of head and flow rate tested, the direct drive automobile alternator may not be the ideal type of generator to utilize, due to inefficiencies when operating at low rotational speed, and utilization of a large fraction of the power generated to energize the coils that provide the magnetic field. One recommendation is to consider the use of a permanent magnet alternator that can provide power over a greater range of rotation speeds, and critically, not consume power in its operation. 


\section{Conclusions}

Following adjustments to nozzle position and mounting of the Guelph Firefly unit, testing will recommence with varied flows and heads.

Modeling the alternator is difficult: in addition to rotation speed and torque, performance is impacted by field strength. This makes it difficult to separate the effects of alternator performance from turbine performance. Future testing will separate the Firefly from the alternator. The Firefly turbine will be characterized by testing on a dynamometer over a range of torque and rotation rates. Separate dynamometer testing of the alternator will allow determination of the relative importance of alternator optimization (e.g. field strength) compared to turbine configuration (e.g. nozzle alignment). Alternative turbines of different configurations and lower parts counts will also be designed and tested, and compared to the Firefly.

This paper has described the initial stages of this research project. Additional testing of the current Firefly unit is currently being conducted, and work has begun on the design of different turbines with the goal of further optimizing ease of construction, performance and reliability. The results of the continued testing will be used to draw conclusions on the appropriateness of the current Firefly, and improved designs, in M'muock, Cameroon.

\section{References}

[1] International Evaluation Group - World Bank, The Welfare Impact of Rural Electrification: A Reassessment of the Costs and Benefits, 2008, URL: http://siteresources.worldbank.org/EXTRURELECT/Resources/full_doc.pdf [last accessed January 11, 2011].

[2] A.A. Williams and R. Simpson, Pico hydro - Reducing technical risks for rural electrification, Renewable Energy 34, 2009, pp. 1986 - 1991.

[3] G. Gunkel, Hydropower - A green energy? Tropical reservoirs and greenhouse gas emissions, Clean - Soil, Air, Water 37 - 9, 2009, pp. 726 - 734.

[4] J. Hertlein, Project start document - Small Scale Water Turbine for Cameroon. Report. Green Step e.V., 2010.

[5] J. Portegijs, J. The Firefly Micro Hydro System, 2003. URL: http://www.microhydropower.net/mhp_group/portegijs/firefly_bm/ffbm_index.html [last accessed January 11, 2011] 